\title{
Light-induced mass transport in amorphous chalcogenides/gold nanoparticles composites
}

\author{
M.L.Trunov ${ }^{1,2}$, P.M. Lytvyn ${ }^{3}$, P.M. Nagy ${ }^{4}$, O.S. Oberemok ${ }^{3}$, M.O. Durkot ${ }^{1}$, A.A. Tarnaii ${ }^{1}$, I.V. Prokopenko ${ }^{3}$, \\ V.M. Rubish ${ }^{1}$ \\ ${ }^{1}$ Uzhgorod Scientific-Technological Center of IIR NAS Ukraine, Zamkovi shody str. 4a, 88000 Uzhgorod, Ukraine \\ ${ }^{2}$ Uzhgorod National University, 3, Narodna sq., 88000 Uzhgorod, Ukraine \\ ${ }^{3}$ V. Lashkaryov Institute of Semiconductor Physics, National Academy of Sciences of Ukraine, \\ 41, prospect Nauky, 03028 Kyiv, Ukraine \\ ${ }^{4}$ Recearch Centre for Natural Science, Hungarian Academy of Sciences, Pusztaszeri st. 59-67, 1025 Budapest, Hungary
}

\begin{abstract}
We have established that mass-transport processes in two types of amorphous materials, based on light-sensitive inorganic compounds like $\mathrm{Se}$ and $\mathrm{As}_{20} \mathrm{Se}_{80}$ chalcogenide glasses $(\mathrm{ChG})$, can be enhanced at the nanoscale in the presence of localized plasmonic fields generated by visible light in gold nanoparticles (GNPs), if the condition of surface plasmon resonance (SPR) is fulfilled. It was found that irradiation by light in the presence of SPR produces profound surface nanostructurizations, and variation in topography follows closely and permanently the underlying near field intensity pattern. We have proposed a model of mass-transport in which the existence of moving anisotropic dipolar units and internal electric field in $\mathrm{ChG}$ as a main driving force of this movement is suggested.
\end{abstract}

Keywords: amorphous chalcogenides, surface plasmon, noble metal nanoparticles, nearfield illumination, lateral mass-transport, photoplastic effect, nanostructurization.

Manuscript received 10.07.13; revised version received 05.09.13; accepted for publication 23.10.13; published online 16.12.13.

\section{Introduction}

The phenomenon of light-induced mass transport refers to a material's ability to show movement of mass (e.g. atomic or molecular structural units in a solid array) from one location to another as a result of irradiation by light, as a rule actinic (band-gap or close to it). The parameters of induced mass-transport depend on irradiation conditions: directions and velocity of the mass movement depends on the direction of polarization of exciting light, while the value of the induced surface distortion (trench or valley in the irradiated place) on the irradiation dose. Materials featuring this phenomenon have found applications in optical storage drives with high-density recording, holography and lithography, integrated optics. Among variety of photosensitive materials, chalcogenide glasses demonstrate relatively high mass transport [1] under the influence of light and allow obtaining surface topography purely by means of optical method, and, as revealed by further research, even at relatively low intensities of light [2-4]. This method typically uses a projection of an interference pattern that is formed by the interaction of two or more coherent plane waves on the surface of a ChG film $[5,6]$.

The topographical changes of a surface which are obtained by using this method are limited by the lateral size due to the phenomenon of light diffraction, which does not allow manufacturing working elements of the nanometer scale.

One of the ways to overcome the diffraction barrier can be the use of near light field (near-field) of metallic nanoparticles (NPs) integrated into a $\mathrm{ChG}$ film as plasmonic nanostructures [7]. Generation of localized plasmons in the noble metal NPs is widely used for enhancement of light interaction with a matrix surrounding these plasmonic nanostructures. Incident light, absorbed by NPs and being converted into collective oscillations of free electrons in the NPs leads to a strong enhancement of the local electric field. This phenomenon titled as a surface plasmon resonance (SPR) occurs in the case of noble metal NPs in the visible spectral region and can be considered as generation of evanescent waves in the near-field region $[8,9]$. 
The main idea of this contribution is to investigate the influence of near-field irradiation on the formation of surface reliefs in $\mathrm{ChG}$ films with integrated $\mathrm{Au}$ NPs under the appropriate excitation of SPR by means of laser radiation. Instead of Kretschmann configuration that employes the variation of optical properties of the films [10-13], the special case of photoplastic effect [14] (light-induced mass-transport) in amorphous chalcogenides will be used. Direct photoinduced fabrication of the reliefs with different shape and scale on film surface by lateral mass-transport under sub-wavelength surface plasmon near-fields is expected. It will allow us nanopatterning of the photosensitive films having the main advantage of plasmon nanolithography (to overcome the diffraction limit). On the other hand, more complex surface reliefs can be generated in a single step due to the possibility to tune the shape of the plasmon near-field radiation by adjusting the geometry of NPs. Another feature will be the mapping of surface plasmon intensity distribution.

\section{Materials and experiment}

Using rapid thermal annealing, an array of randomly arranged $\mathrm{Au}$ NPs was formed on sapphire or Corning glass substrates with conductive indium tin oxide (ITO) layer. At the first stage, thin $(10-20 \mathrm{~nm})$ films of gold were condensed on the substrates by the method of thermal evaporation. The subsequent annealing in argon atmosphere at temperatures 400 to $700{ }^{\circ} \mathrm{C}$ led to the formation of randomly distributed hemispherical Au NPs with the diameter from 10 to $100 \mathrm{~nm}$, which reveal the SPR in the vicinity of $520 \ldots .580 \mathrm{~nm}$. The surface morphologies of the annealed thin films of gold with different initial thicknesses and thermal prehistory were characterized by AFM as shown in Figs 1a, 1b. These morphologies clearly reveal the formation of NPs in annealed films. The optical transmission spectra of the prepared samples were measured with Ocean Optics spectrophotometer. It was shown that the SPR peak reveals the maximal value in the vicinity of 530-580 nm.

At the second stage, $\mathrm{ChG}$ films with the thickness of $50 \ldots 100 \mathrm{~nm}$ were applied on the top of Au NPs with the use of thermal evaporation using a deposition rate 1.5 to $3 \mathrm{~nm} \cdot \mathrm{s}^{-1}$. The thickness of $\mathrm{ChG}$ films was measured with AFM on reference samples (without $\mathrm{Au}$ NPs as sublayers). Note that as plasmon-induced effect on the $\mathrm{ChG}$ film structure is localized on the distances of near field existence within the range 20 to $100 \mathrm{~nm}$, we should limit the thickness of ChG layer by $100 \mathrm{~nm}$ in $\mathrm{Au}$ NPs/ChG film composite. The resulting structures of the samples and their optical transmittance (both as a pure film with a thickness of $100 \mathrm{~nm}$ and being deposited on $\mathrm{Au}$ NPs with the average size of 40-80 nm) are shown in Fig. 2. Amorphous $\mathrm{Se}(\mathrm{a}-\mathrm{Se})$ and $\mathrm{As}_{20} \mathrm{Se}_{80}$ were selected as the film forming compositions. The presence of significant mass-transport in $\mathrm{As}_{20} \mathrm{Se}_{80}$ films [15] served as a criterion for its choice; while a-Se film was of interest
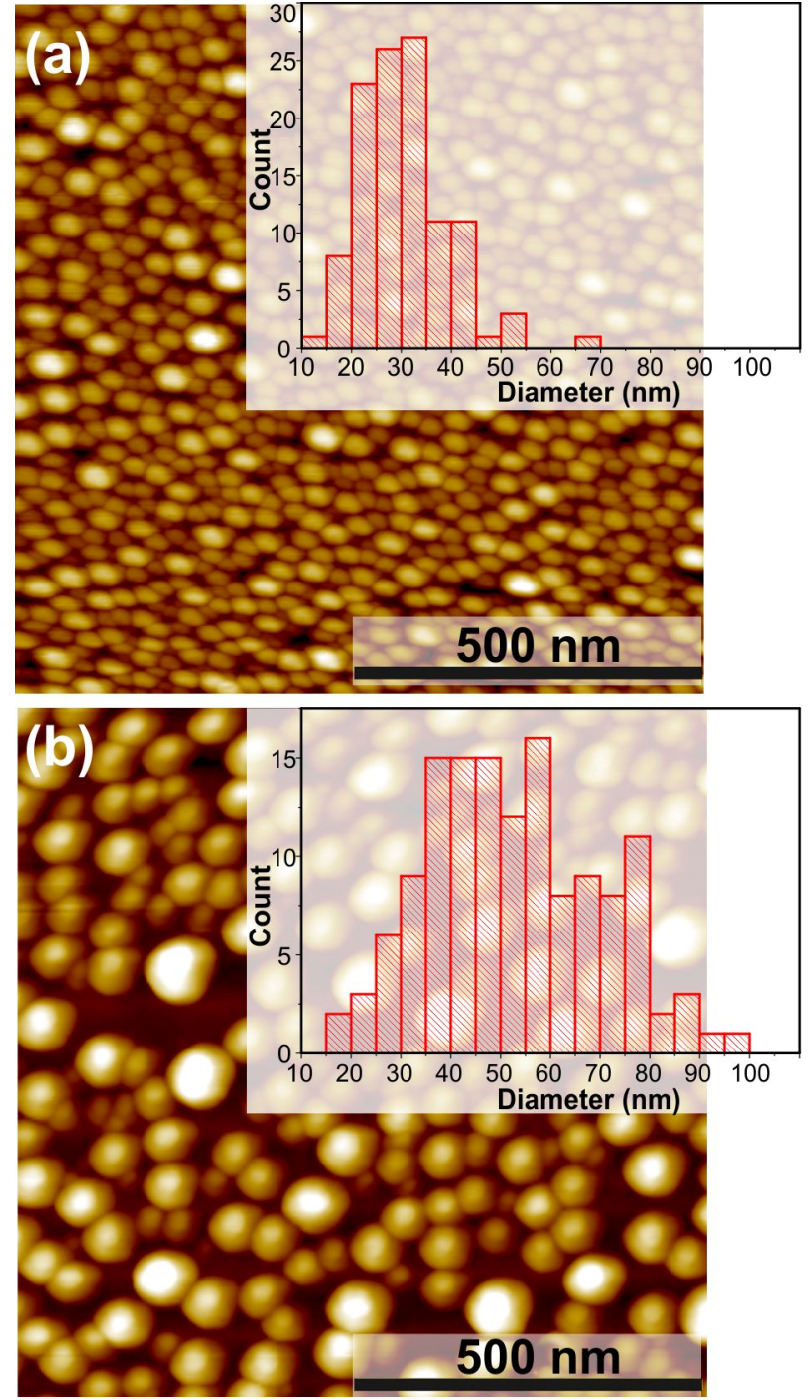

Fig. 1. AFM images of Au NPs with different diameters on the sapphire substrates covered with ITO $(a-b)$ and corresponding size histograms (inserts).

due to the fact that it is the only ChG composition with the opposite direction of motion of the material (away from light) [16].

The $\mathrm{Au}$ NPs that were used for excitation of nearfield illumination through localized surface plasmons satisfy the conditions for SPR excitation in the visible spectral region (as shown by the arrow in the Au NPs curves in Fig. 2), where most of the basic ChG of As-Se system has maximum to photoinduced response. However, if those NPs are covered with thin ChG layer, the SPR spectra changed according to the differences in the refractive index, thickness of $\mathrm{ChG}$ layer and moreover, further shifted due to the photostimulated changes of its optical parameters. Using this way, we obtained an efficient method of influencing the light induced structural transformations of the $\mathrm{ChG}$ film and of measuring the kinetics of the process. It is also obvious that to achieve the objectives of the work, the 
frequency of the incident beam that causes SPR must coincide with absorption band of $\mathrm{ChG}$, or at least, be in its vicinity. That is why we used in-situ measurements of transformation of SPR spectra during amorphous layer deposition and interrupts the process after reaching the appropriate thickness of the film. The comparative analysis of the transmission spectra before and after deposition of ChG film shows that the SPR frequency is shifted to the red spectral region by $70 \ldots 150 \mathrm{~nm}$, depending on the thickness of the $\mathrm{ChG}$ film and geometric characteristics of the array of gold nanoparticles. The peak is in the $680 \ldots 730 \mathrm{~nm}$ range (see appropriate curves for pure $\mathrm{Au}$ NPs and $\mathrm{ChG}$ film/Au NPs structures in Fig. 2). This fully satisfies the conditions above, since the width of the band gap of $\mathrm{ChG}$ films of As-Se system which were investigated is $E_{g} \approx 1.9 \ldots 2 \mathrm{eV}$ at the absorption coefficient $\alpha=10^{3} \mathrm{~cm}^{-1}$. It corresponds to the laser wavelengths $630 \ldots 650 \mathrm{~nm}$ (as shown by the bold arrow in Fig 2).

The samples were irradiated from the bottom through a transparent substrate using unfocused single beam of the $650-\mathrm{nm}$ laser of random polarization (Fig. 3).

Irradiation time ranged from a few minutes to few hours at $80 \ldots 300 \mathrm{~mW} / \mathrm{cm}^{2}$ intensity. This is the level of intensity which is usually used in the formation of surface reliefs in ChG films by the holographic method. Taking into account the peculiarities of in situ measurements of surface deformation by the method of probe microscopy [17], optical recording of the surface relief was studied in real time using AFM (Nanoscope IIIa Dimension 3000, Digital Instruments/Bruker) with a special integrated device that allowed conducting both the light irradiation of the sample and research kinetics of corresponding topographical changes of its surface simultaneously.

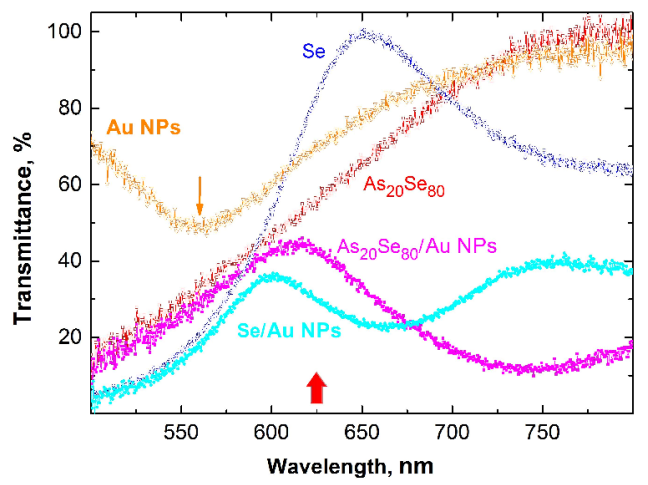

Fig. 2. Optical transmittance spectra of appropriate Au NPs and photosensitive structures: $\mathrm{ChG}$ film and $\mathrm{ChG}$ film / $\mathrm{Au}$ NPs composites. The compositions are indicated directly on the image. Thickness of the ChG film is $100 \mathrm{~nm}$; the Au NPs corresponds to Au NPs array presented in Fig. 1b. Arrows show the initial position of SPR and the wavelength of the laser source that was used for irradiation of composite structures.

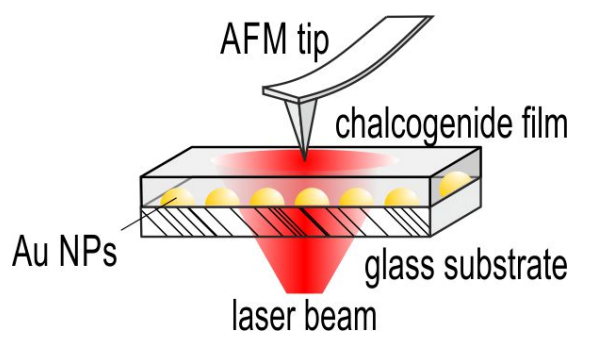

Fig. 3. Scheme of the experimental setup. Components along the direction of the laser beam are indicated directly on the image.

\section{Results and discussion}

In the AFM study, the reference surface of $\mathrm{As}_{20} \mathrm{Se}_{80} / \mathrm{Au}$ NPs sample was investigated before exposure by light. It was found that the morphology of the array of Au NPs, despite the presence of a thin $(100 \mathrm{~nm})$ layer of $\mathrm{As}_{20} \mathrm{Se}_{80}$ film, can be reliably detected in the tapping AFM mode (see the reference surface in Fig. 4a). Figs $4 b$ and $4 c$ show the change of the surface topography of the sample after its irradiation with light for 5 and $7 \mathrm{~min}$, respectively. The analysis of these dynamics showed that its roughness (root mean square, RMS) increased from $1.75 \mathrm{~nm}$ for the reference surface to 1.87 after $5 \mathrm{~min}$ of exposure and to 2.54 after $7 \mathrm{~min}$. Fig. $4 \mathrm{c}$ also shows that the surface topography has changed essentially relative to the reference surface and corresponds to the local distribution of the electromagnetic field intensity of surface plasmons due to the concentration of material in the film within the areas of the local maximum of the field. This follows from the general laws of photoinduced mass transport in $\mathrm{As}_{20} \mathrm{Se}_{80}$ films, including the fact that the movement of material in this composition occurs in the direction towards areas of the maximum intensity of light [15].

At the same time, the opposite result was obtained in the study of a-Se/Au NPs samples (Fig. 5). Due to the fact that the direction of photoinduced mass transport in amorphous selenium is opposite to $\mathrm{As}_{20} \mathrm{Se}_{80}$ composition [16], the material accumulates in the places of the local minimum of light (Figs $5 \mathrm{~b}$ and $5 \mathrm{c}$ ). This results in a significant reduction in surface roughness of the sample under irradiation with light: from RMS of $1.33 \mathrm{~nm}$ for reference surface (Fig. 5a) to $0.97 \mathrm{~nm}$ after $20 \mathrm{~min}$ of illumination (Fig. 5b) and caused by blurring of the initial picture of the relief after $70 \mathrm{~min}$ of exposure (RMS $=0.67 \mathrm{~nm}$, Fig. 5c). It should also be noted that excitation of localized surface plasmons is always accompanied by a local increase in the ambient temperature [18]. Since amorphous selenium has softening temperature close to the room temperature $\left(38^{\circ} \mathrm{C}\right)$, the obtained result may be the additive sum of matter motion due to both photoinduced mass transport to the local minima of light and through increasing the fluidity, which is the result of local heating. 

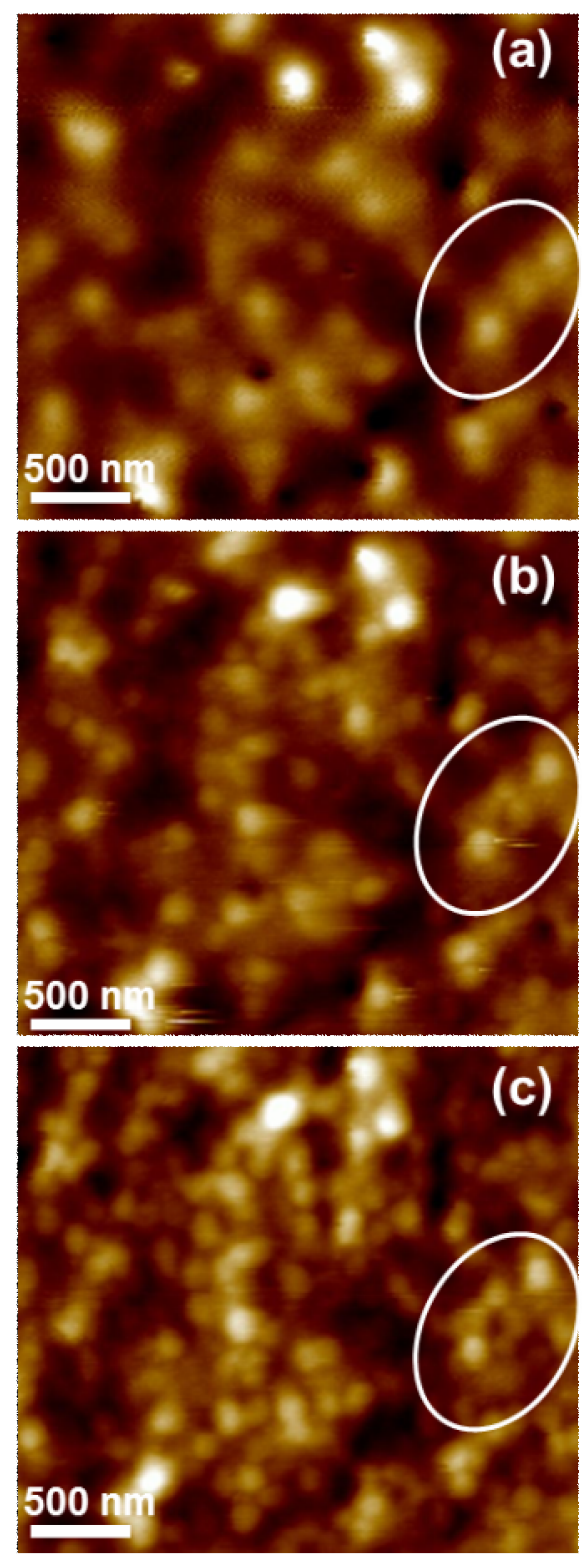

Fig. 4. AFM images of the topography of $\mathrm{As}_{20} \mathrm{Se}_{80}$ film placed on the Au NPs before irradiation $(a)$. The ChG film thickness is $100 \mathrm{~nm}$. The same area after irradiation with $650 \mathrm{~nm}$ laser beam $\left(100 \mathrm{~mW} / \mathrm{cm}^{2}\right)$ for $5(b)$ and $7 \mathrm{~min}(c)$. Appropriate places in the circles were taken, and these illustrate initial surface topography and surface relief increasing due to plasmon intensity distribution inside the glass matrix.

Note that we omit any numerical simulation and/or fitting of the near-field intensity distributions for comparing it with in situ recorded topography changes (at least at this stage of experiment). This is due to the absence of any ordering in Au NPs array that led to very complex-shape intensity of plasmon radiation with a corresponding complex impact on the photosensitive ChG film and appropriate surface relief. With ordering $\mathrm{Au}$ NPs, these relationships awaits further studies and such experiments and a complete model will be discussed with more details in another publication. But, the phenomena described above for ChG of $\mathrm{As}_{20} \mathrm{~S}_{80}$ and a-Se films on $\mathrm{Au}$ NPs show the similar dependences upon intensity, spectrum, and exposure time of excitation light as for pure a-Se and $\mathrm{As}_{20} \mathrm{~S}_{80}$ film during masstransport $[13,19,20]$, which imply the same underlying mechanisms.

The mechanism of the light-induced mass-transport in ChG is still not well studied, despite some attempts to develop a unified model with a complete description of the basic microscopic mechanism. From the macroscopic point of view, for phenomenological explanations several models has been proposed [1, 19-21]. Among them, the most widely used model is the gradient force one [1] (the model was originally proposed for understanding anisotropic deformations in azobenzenefunctionalized polymers [20]) that based on the fact that the electric field gradient of the writing light along the grating vector causes a force on dipoles (dipolar defects or other anisotropic structural units, native or photoinduced) on the scale of about 3 coordination spheres [22] leading to mass-transport due to their interaction and/or rearrangement.
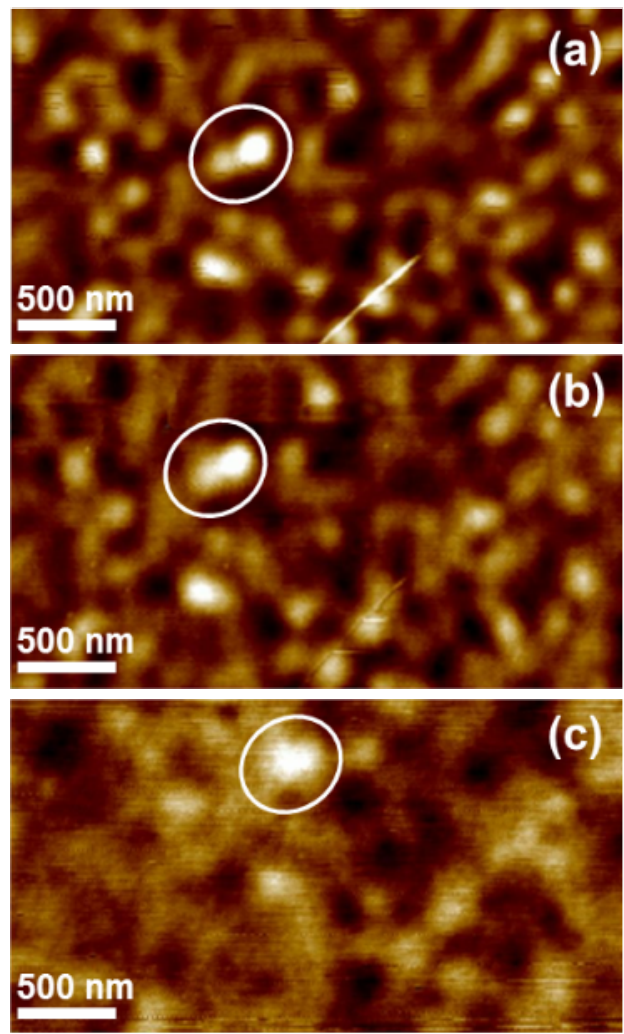

Fig. 5. AFM images of the topography of a-Se film placed on the $\mathrm{Au}$ NPs before irradiation $(a)$. The $\mathrm{ChG}$ film thickness is $100 \mathrm{~nm}$. The same area after irradiation with $650-\mathrm{nm}$ laser beam $\left(100 \mathrm{~mW} / \mathrm{cm}^{2}\right)$ for $20(b)$ and $70 \mathrm{~min}(c)$. Appropriate places in the circles were taken, and they illustrate initial surface topography and flattening of the film surface due to plasmon intensity distribution inside the glass matrix. 
Note that the phenomenon occurs far below the glass transition temperature and the thermal action should be mostly excluded. According to the model that was presented in [23], the temperature rise at the beam center is $\sim 24 \mathrm{~K}$, when $\mathrm{ChG}$ bulk glass $\left(\mathrm{As}_{2} \mathrm{~S}_{3}\right)$ is irradiated for $1800 \mathrm{~s}$ by the laser $\left(0.33 \mathrm{~W} / \mathrm{cm}^{2}\right)$ with medium absorption of the film $\left(\sim 10^{3} \mathrm{~cm}^{-1}\right)$. In our case, low excitation intensities and heat dissipation in a very thin film $(100 \mathrm{~nm})$ decrease this value essentially.

On the other hand, the light-induced (athermal) softening of glassy matrix takes place (viscosity lowers to $\sim 10^{11} \mathrm{~Pa} \cdot \mathrm{s},[14]$ ) that enhances motion of the dipoles under the driving optical force. It means that the gradient moves dipoles (native and/or created by the light) in a matrix softened by the lightening itself. Various spectroscopic studies have shown the existence of short Se-chains in Se-rich glasses [24]. We suggest that short Se segments may act as polarization sensitive anisotropic structural units that can be rearranged under illumination by polarized light in the frame of the mechanism that was adopted to account for photoinduced optical anisotropies [25]. Another possibility for matter motion is photoinduced dipoles created by light after scission of the weak bonds of over-coordinated atoms (e.g. hypervalent defects in a-Se, i.e., three-fold and four-fold coordinated Se atoms [26]). Under optical electric field, the photoinduced dipoles can lower their energy by changing configuration and/or aligning in the direction along or perpendicular to the polarization of incident light (in case of linear polarization). For both types of dipoles (native and photoinduced) their reorientation, rearrangement and attraction could cause mass-transport only in the presence of driving force and the latter is the above mentioned electric-field gradient force. Existence of this force in the case of $\mathrm{ChG}$, however, suffers from difficulties due to some points (see e.g. [27] for details). With this reason, we try to propose other driving force that can causes the masstransport in ChG. This driving force may arise from anisotropic diffusion of photoexcited carriers leading to appearance of internal electric field. Additional evidence of this hypothesis is delivered by AFM measurements of surface profile and corresponding surface potential for $\mathrm{As}_{20} \mathrm{Se}_{80}$ and a-Se films that were taken in situ under polarized laser irradiation focused in $\sim 2-\mu \mathrm{m}$ spot. Modification of the electrical properties under irradiation was studied by Kelvin probe force microscopy technique (KPFM), one of electric field sensitive AFM modes, dealing with surface potential [28].

Isotropic and anisotropic deformations in a-Se and $\mathrm{As}_{20} \mathrm{Se}_{80}$ film have appeared irrespective of the film thickness and depends on the time of exposure only. For both films, isotropic expansion appears at first (Figs 6a and 7a), which gradually transforms to an anisotropic Mshaped deformation with exposure time (Figs $6 \mathrm{~b}$ and $7 b)$. However, the central peak and the peripheral valleys was detected for $\mathrm{As}_{20} \mathrm{Se}_{80}$ film (Fig. 6b), while the opposite situation (the valley and the peripheral peaks)
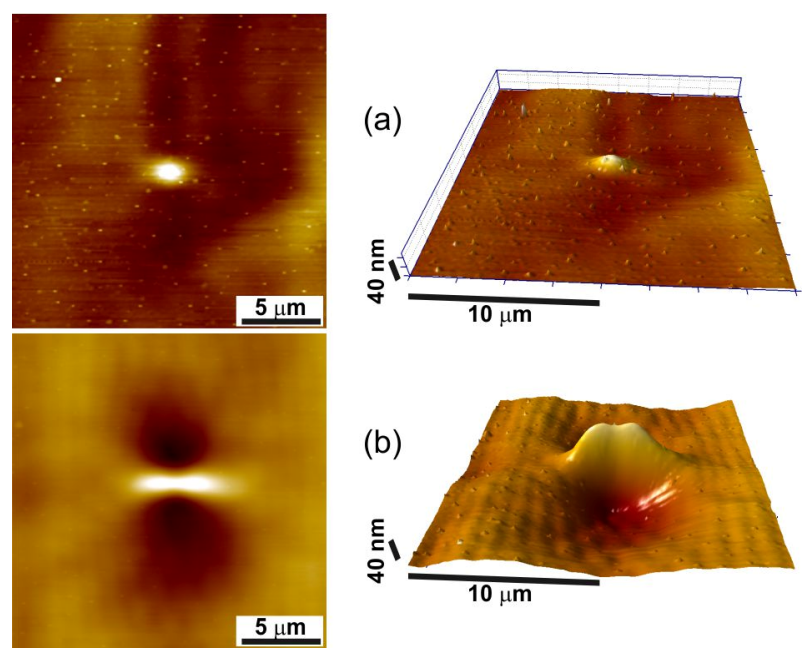

Fig. 6. AFM images of an isotropic expansion (a) and an anisotropic surface relief (b) in $\mathrm{As}_{20} \mathrm{Se}_{80}$ film with thicknesses of $1 \mu \mathrm{m}$ after exposures of 10 and $2400 \mathrm{~s}$, respectively, by linearly polarized light $(2.0 \mathrm{eV})$. The polarization of the laser is oriented vertically. 2D and corresponding 3D images are presented.
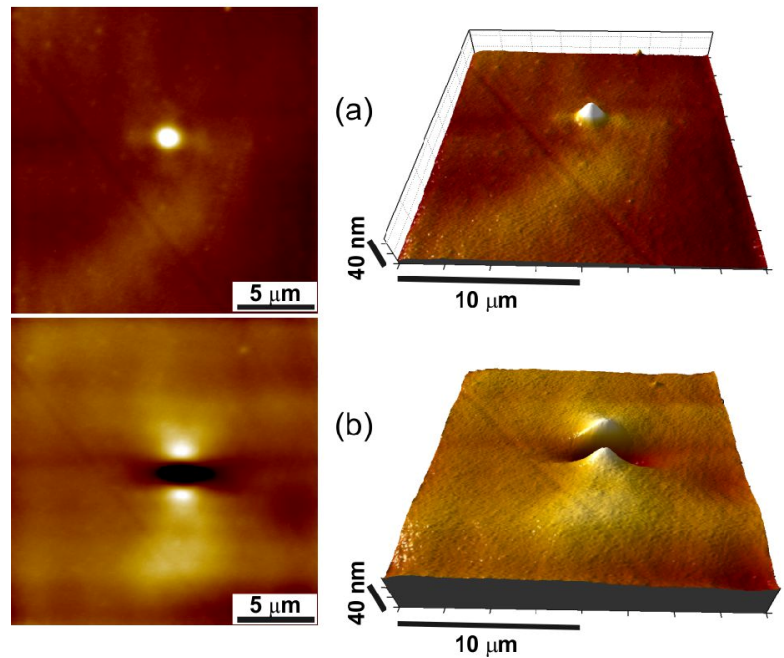

Fig. 7. AFM images of $(a)$ an isotropic expansion and $(b)$ an anisotropic surface relief in a-Se film with thicknesses of $1 \mu \mathrm{m}$ after exposures of 10 and $500 \mathrm{~s}$, respectively, by linearly polarized light $(2.0 \mathrm{eV})$. The polarization of the laser is oriented vertically. $2 \mathrm{D}$ and corresponding $3 \mathrm{D}$ images are presented.

was revealed for a-Se (Fig. 7b). In both cases, the long axes of the M-shaped zone are oriented along the polarization direction. So, it means that at least two main types of surface relief (SR) can be distinguished in $\mathrm{ChG}$ according to their formation mechanism and their properties: (i) small scalar SR induced by either volume expansion or shrinkage and (ii) giant vectorial $S R$ induced by lateral mass transport under polarized light. The direction of mass motion depends on the composition. At the same time, appropriate KFPM signals (surface potential) appear simultaneously with 
$\mathrm{SR}$, if the polarized laser irradiation is switched on (see Figs $6 \mathrm{a}, 7 \mathrm{a}$ and Figs $8 \mathrm{a}, 8 \mathrm{e}$ ), increase to some saturation level and after that the blurring or even local decreasing occurs (Fig. 9d, 9h). The maximum of saturated surface potential occurs for $5 \mathrm{~min}$ of exposure, while the peakto-valley difference in anisotropic regimes tends to increase with the absorbed dose without explicit saturation (Figs $6 \mathrm{~b}$ and $7 \mathrm{~b}$ ).
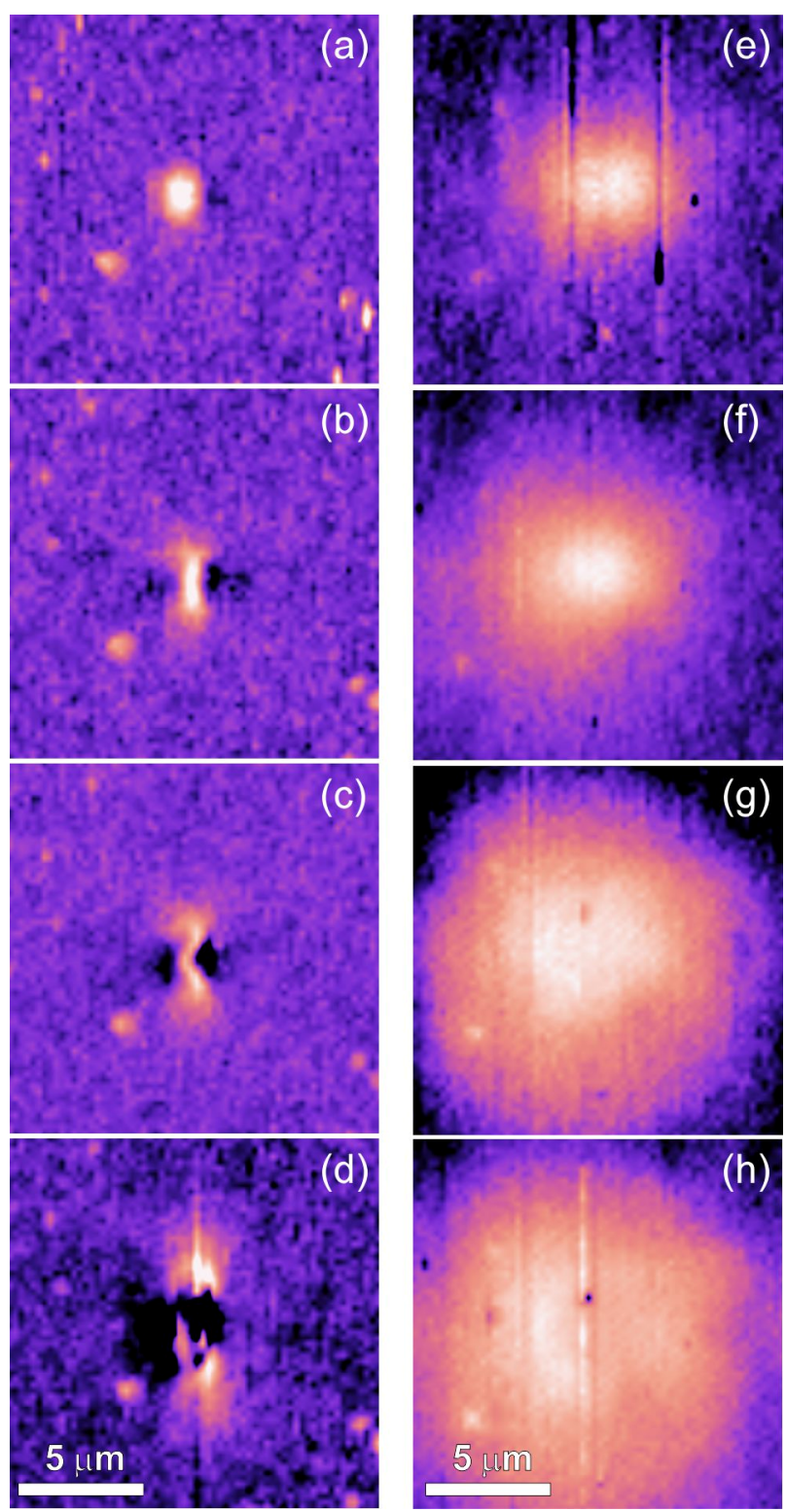

Fig. 8. Surface potential (SKPFM) distribution as a function of exposure time for irradiated $1 \mu \mathrm{m}$-thick $\mathrm{As}_{20} \mathrm{Se}_{80}(a-d)$ and a-Se films $(e-h)$ placed on the glass substrates covered with ITO. The illumination source is a linearly polarized solid state laser $(650 \mathrm{~nm})$, with the intensity of $\sim 2 \mathrm{~W} / \mathrm{cm}^{2}$ in a focused spot of $\sim 2 \mu \mathrm{m}$ in diameter. The electric-field direction is horizontal. The time of exposure was as follows: $8(a), 34(b), 52(c), 112$ $(d), 5(e), 17(f), 34(g), 43$ minutes $(h)$.
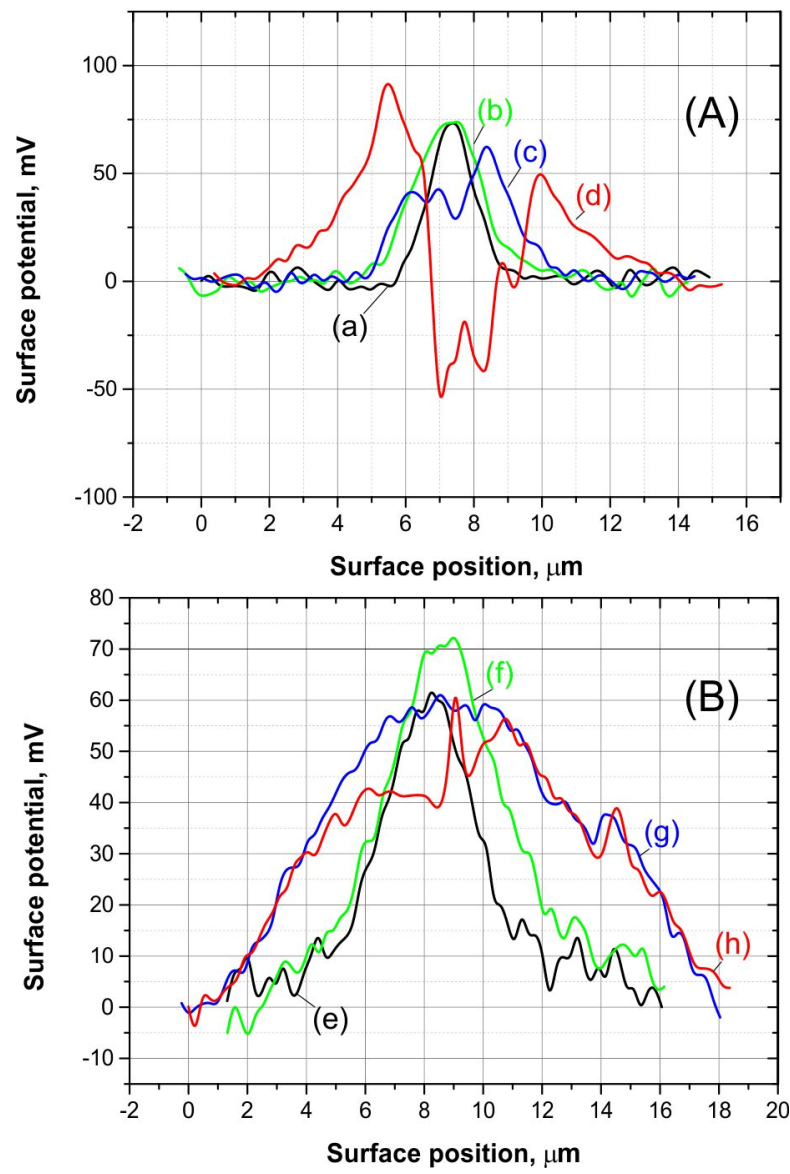

Fig. 9. SKPFM profiles as a function of exposure time for irradiated $1 \mu \mathrm{m}$-thick $\mathrm{As}_{20} \mathrm{Se}_{80}(a)$ and a-Se films $(b)$ obtained from appropriated images $(a-h)$ in Fig. 8. The cross-sections were taken perpendicular to the polarization plane.

It should be also noted that the growth of the anisotropic SR is delayed with respect to the appropriate M-shaped profile appearing due to the surface potential in $\mathrm{As}_{20} \mathrm{Se}_{80}$ film. The similar result was obtained for holographic exposure that generates the polarized illumination pattern, and the confirmation will be presented elsewhere.

Thus, we conclude that the processes of photomodification of the electric parameters of $\mathrm{ChG}$ layers associated with volume charge appearance and redistribution could be the main reason of the masstransport. Additionally, we can stimulate further this phenomena with using the local electric field of surface plasmons when $\mathrm{ChG}$ cover a metallic (e.g. Au) NPs exposed to light near their SPR plasmon resonance which should to overlap with $\mathrm{ChG}$ absorption band.

\section{Conclusion}

In this contribution, we have shown that controlled changes in the surface topography of $\mathrm{ChG}$ films are possible through near-field illumination that occurs at excitation of localized surface plasmons. By means of 
integration of $\mathrm{Au}$ NPs in a ChG film, a corresponding photosensitive structure was obtained that was characterized by an effective overlapping of SPR frequency and the absorption band of ChG. Under bandgap irradiation, the material moves either towards the areas of maximum light intensity $\left(\mathrm{As}_{20} \mathrm{Se}_{80}\right)$, or, respectively, away from them (a-Se). It allows the mapping of surface plasmon intensity distribution.

From the obtained results, there follows the possibility of changing surface topography of a ChG film by means of changing the shape, size and geometry of $\mathrm{Au}$ NPs. Some additional possibilities regarding controlled changes of surface topography by the intensity and polarization of near-field can be expected through the integration of ordered arrays of Au NPs in ChG.

\section{Acknowledgements}

One of the authors, M.L.T. acknowledges support from International Visegrad Fund. A part of this work was supported by the Ukrainian National Academy of Sciences through the project $6-13 \mathrm{H}$.

\section{References}

1. A. Saliminia, T.V. Galstian, and A. Villeneuve, Optical field-induced mass transport in $\mathrm{As}_{2} \mathrm{~S}_{3}$ chalcogenide glasses // Phys. Rev. Lett., 85, p. 41124115 (2000).

2. M.L. Trunov, Polarization-dependent laser-induced giant mass transport in glassy semiconductors // JETP Lett. 86 (5), p. 313-316 (2007).

3. M.L. Trunov, Photoplastic effect in non-crystalline materials: a nanoindentation study // J. Phys. D: Appl. Phys. 41(7), 074011 (2008).

4. M.L. Trunov, V.S. Bilanich, and S.N. Dub, The nonHookian behavior of chalcogenide glasses under irradiation: A nanoindentation study // J. Non. Cryst. Solids, 353(18), p. 1904-1909 (2007).

5. M. Fischer, T. Galstian, R. Vallée, and A. Saliminia, Surface and volume contributions to total diffractional efficiency in $\mathrm{As}_{2} \mathrm{~S}_{3}$ thin film glasses // Synthetic metals, 127(1), p. 303-306 (2002).

6. V. Palyok, I.A. Szabó, D.L. Beke, and A. Kikineshi, Surface grating formation and erasing on a-Se films // Appl Phys A, 74(5), p. 683-687 (2002).

7. S. Jayawardhana, L. Rosa, S. Juodkazis, and P.R. Stoddart, Additional enhancement of electric field in surface-enhanced Raman scattering due to Fresnel mechanism // Sci. Repts. 3, p. 2335 (2013).

8. A.N. Grigorenko, N.W. Roberts, M.R. Dickinson, and Y. Zhang, Nanometric optical tweezers based on nanostructured substrates // Nature Photonics, 2(6), p. $365-370$ (2008).

9. H.J. Lezec, and T. Thio, Diffracted evanescent wave model for enhanced and suppressed optical transmission through subwavelength hole arrays // Opt. Express, 12(16), p. 3629-3651 (2004).

10. J. Le Person, F. Colas, C. Compere, M. Lehaitre, M.L. Anne, C. Boussard-Plédel, B. Bureau, J.-L. Adam, S. Deputier, and M. Guilloux-Viry, Surface plasmon resonance in chalcogenide glass-based optical system // Sensors and Actuators B: Chemical, 130(2), p. 771-776 (2008).

11. R. Jha, and A.K. Sharma, High-performance sensor based on surface plasmon resonance with chalcogenide prism and aluminum for detection in infrared // Opt. Lett. 34(6), p. 749-751 (2009).

12. R. Jha, and A.K. Sharma, Chalcogenide glass prism based SPR sensor with $\mathrm{Ag}-\mathrm{Au}$ bimetallic nanoparticle alloy in infrared wavelength region // J. Opt. A: Pure and Appl. Opt. 11(4), 045502 (2009).

13.Z.L. Sámson, S.C. Yen, K.F. MacDonald, K. Knight, S. Li, D.W. Hewak, D.P. Tsai, and N.I. Zheludev, Chalcogenide glasses in active plasmonics // Physica Status Solidi (RRL)-Rapid Res. Lett. 4(10), p. 274276 (2010).

14. S.N. Yannopoulos, and M.L. Trunov, Photoplastic effects in chalcogenide glasses: A review // Physica Status Solidi (b), 246(8), p. 1773-1785 (2009).

15. M.L. Trunov, P.M. Lytvyn, and O.M. Dyachyns'ka, Alternating matter motion in photoinduced mass transport driven and enhanced by light polarization in amorphous chalcogenide films // Appl. Phys. Lett., 97(3), p. 031905 (2010).

16. M.L. Trunov, P.M. Lytvyn, S.N. Yannopoulos, I.A. Szabo, and S. Kökényesi, Photoinduced masstransport based holographic recording of surface relief gratings in amorphous selenium films // Appl. Phys. Lett. 99(5), 051906 (2011).

17. M.L. Trunov, P.M. Lytvyn, P.M. Nagy, and O.M. Dyachyns'ka, Real-time atomic force microscopy imaging of photoinduced surface deformation in $\mathrm{As}_{\mathrm{x}} \mathrm{Se}_{100-\mathrm{x}}$ chalcogenide films // Appl. Phys. Lett. 96(11), p. 111908 (2010).

18. A.O. Govorov, W. Zhang, T. Skeini, H. Richardson, J. Lee, and N.A. Kotov, Gold nanoparticle ensembles as heaters and actuators: melting and collective plasmon resonances // Nanoscale Res. Lett. 1(1), p. 84-90 (2006).

19. J. Kumar, L. Li, X.L. Jiang, D.-Y. Kim, T.S. Lee, and S. Tripathy, Gradient force: The mechanism for surface relief grating formation in azobenzene functionalized polymers // Appl. Phys. Lett, 72(17), p. 2096-2098 (1998).

20. S. Bian, J.M. Williams, D.Y. Kim, L. Li, S. Balasubramanian, J. Kumar, and S. Tripathy, Photoinduced surface deformations on azobenzene polymer films // J. Appl. Phys. 86(8), p. 4498-4508 (1999).

21. P. Lefin, C. Fiorini, and J.-M. Nunzi, Anisotropy of the photo-induced translation diffusion of azobenzene dyes in polymer matrices // Pure and Appl. Opt.: J. Europ. Opt. Soc. Part A, 7(1), p. 71-82 (1998). 
22. J.M. Lee, G. Pfeiffer, M.A. Paesler, D.E. Sayers, and A. Fontaine, Photon intensity-dependent darkening kinetics in optical and structural anisotropy in a $-\mathrm{As}_{2} \mathrm{~S}_{3}$ : A study of X-ray absorption spectroscopy // J. Non.Cryst. Solids, 114, p. $52-54$ (1989).

23. D. Zhao, H. Jain, Luis C. Malacarne and Paulo R B. Pedreira, Role of photothermal effect in photoexpansion of chalcogenide glasses// Physica Status Solidi (b), 250(5), p. 983-987 (2013).

24. A. Feltz, Amorphous Inorganic Materials and Glasses. Wiley-VCH, New York, 1993.

25. H. Fritzsche, Optical anisotropies in chalcogenide glasses induced by band-gap light // Phys. Rev. B, 52(22), p. 15854-15861 (1995).

26. T. Scopigno, W. Steurer, S.N. Yannopoulos, A. Chrissanthopoulos, M. Krisch, G. Ruocco, and T. Wagner, Vibrational dynamics and surface structure of amorphous selenium // Nature Communs. 2, p. 195 (2011).

27. K. Tanaka, and H. Asao, Photoinduced anisotropic deformation in $\mathrm{As}_{2} \mathrm{~S}_{3}$ glass // Jpn. J. Appl. Phys. 45, p. 1668 (2006).

28. M. Nonnenmacher, M.P. O’Boyle, and H.K. Wickramasinghe, Kelvin probe force microscopy // Appl. Phys. Lett. 58(25), p. 2921-2923 (1991). 